\title{
Hacia una teoría del prólogo: a propósito de Miguel de Unamuno
}

\author{
MARIA BEATRIZ FERRARI Universidad Nacional de Mar del Plata, Argentina / martabeatrizferrari@gmail.com
}

\section{Resumen}

En este artículo partimos de la demanda que el filósofo danés Søren Kierkegaard formulara en su libro Prólogos (1844) acerca de la necesidad de elaborar una teoría del prólogo, algo que más de un siglo después llevó adelante Gerard Genette en su estudio sobre los llamados «paratextos» y que tituló precisamente Umbrales, haciendo referencia a los aledaños del texto. Luego de realizar un rápido recorrido a través de varios textos, entre ellos Cinco prefacios a cinco libros no escritos (1872) de Friedrich Nietzsche, «Fuera-de-libro (Prefacios)» (1972) de Jaques Derrida y Prólogos con un prólogo de prólogos (1975) de Jorge Luis Borges, nos detendremos especialmente en el caso paradigmático de Miguel de Unamuno y en su filiación con Macedonio Fernández. Las conclusiones apuntan a subrayar la novedad que este "género" adquiere en las formulaciones de estos escritores: el gesto autorreferencial de teorizar desde el prólogo sobre el prólogo en un ejercicio de deconstrucción y resignificación del mismo. El lugar privilegiado que ambos asignan al problema teórico de lo marginal versus lo central, de lo abierto versus lo cerrado, de lo concluso versus lo inconcluso responde a una común concepción estética que apuesta por el fragmento, el esbozo o el proyecto provisional deconstruyendo la mímesis realista del XIX.

Palabras clave: paratexto / prólogo / Miguel de Unamuno / Macedonio Fernández

\section{Towards a prologue 's theory: about Miguel de Unamuno}

Abstract

In this paper we start from the request that the danish philosopher Søren Kierkegaard formulated in his book Prólogos (1844) to develop a theory of the prologue, something that more than a century later carried on Gerard Genette in his study on the so-called "paratextos» and that titled precisely Umbrales, making reference to the surroundings of the text. After making a quick tour through several texts, including Cinco prefacios a cinco libros no escritos (1872) by Friedrich Nietzsche, «Fuera-de-libro (Prefacios)» (1972) by Jacques Derrida and Prólogos con un prólogo de prólogos (1975) by Jorge Luis Borges, we stop especially in the paradigmatic case of Miguel de Unamuno and his affiliation with Macedonio Fernández. The conclusions aim to emphasize the novelty that this "gender» acquires in the formulations of these writers: the self-referential gesture of theorizing from the prologue on the prologue in an simultaneous exercise of deconstruction and resignification. The privileged place that both assign to the theoretical problem of the marginal versus the central, the open versus the closed, the conclusive versus the unfinished responds to a common aesthetic conception that bets on the fragment, the outline or the provisional project deconstructing the realistic mimesis of the XIX century.

Key words: prologue / paratexto / Miguel de Unamuno / Macedonio Fernández

Fecha de recepción: 25/10/2017; fecha de aceptación: 15/12/2017

Para citar este artículo: Ferrari, Marta Beatriz (2018). «Hacia una teoría del prólogo: a propósito de Miguel de Unamuno». El taco en la brea 7 (diciembre-mayo), 22-33 Santa Fe, Argentina: UNL. DOI: https:// doi.org/10.14409/tb.voi7.7352 
Escribir un prólogo es como afilar una guadaña, como afinar una guitarra, como hablar con un niño, como escupir por la ventana (...). Escribir un prólogo es como llamar a alguien a su puerta para gastarle una broma, como pasar por delante de la ventana de una muchacha y mirar para los adoquines, es como dar bastonazos al aire o al viento; como levantar el sombrero sin saludar a nadie. Søren Kierkegaard, Prólogos (1844)

En 1844, Søren Kierkegaard publica en Copenhague una breve obra titulada Prólogos y subtitulada «Lectura ligera para ciertos estamentos según tiempo y ocasión», con la particularidad de que atribuye su autoría a un tal Nicolas Notabene. Se trata de ocho prólogos a obras inexistentes concebidos en clave de entretenimiento. El filósofo danés comienza señalando la necesidad de elaborar una teoría del prólogo asentada en el estudio de casos, empresa que en su opinión arrojaría productivos resultados, algo que en cierta medida y más de un siglo después intentó llevar adelante Gerard Genette en su pormenorizado estudio sobre los llamados «paratextos» y que tituló precisamente Umbrales, haciendo expresa referencia a los aledaños del texto. Así lo expresaba Kierkegaard:

Con relación a un libro, un prefacio es una insignificancia y, sin embargo, iQué buena ocasión para la observación no supondría un cuidadoso estudio comparativo de los prefacios! Se ha hecho mucho en la ciencia para clasificar la literatura y ubicar los escritos de cada autor en su época y las épocas en las generaciones, pero nadie piensa en lo que se podría conseguir si se pudiese instruir a algún erudito para leer sólo prefacios, si bien haciéndolo de modo tan exhaustivo que comenzase por los tiempos más remotos, y siguiese a través de los siglos hasta nuestros días. (281)

Kierkegaard, quien como vemos por el epígrafe del presente trabajo, define al prólogo a través de una vasta serie de comparaciones apelando al modo perifrástico para dar cuenta del mismo, subraya el carácter accesorio, menor y lateral del prólogo respecto del núcleo central representado por el texto, al tiempo que le atribuye el talante de una auténtica variable histórica sujeta al devenir no sólo de los tiempos sino sobre todo de las modas literarias, aspectos que tornan al objeto de estudio en materia altamente elusiva, de casi imposible conceptualización y por ello mismo incapaz de someterse a sistematización alguna. Sin embargo, más allá de esto subraya un rasgo central de los mismos; su carácter ritual, atado fija e invariablemente a la costumbre:

Los prefacios llevan la marca de lo incidental, al igual que los dialectos, los giros idiomáticos y los localismos; están sometidos al dominio de las modas en un sentido muy distinto al de los escritos; varían como varía la vestimenta. Unas veces son largos, otras, cortos; unas veces son atrevidos, otras, recatados; unas veces son pulcros, otras, descuidados; unas veces no se les escapan totalmente las debilidades del libro, otras están devastados por la ceguera o reparan en aquellas mejor que ningún otro (...). Y todo esto es puramente ceremonial. Incluso un escritor que en sus escritos desafía a los tiempos, en lo insignificante, es decir, en el prólogo se ajusta a usos y costumbres. (281-282)

Partiendo de las aseveraciones de Hegel quien en su Fenomenología del espíritu sostenía que el prólogo era algo superfluo respecto de la obra filosófica que lo sucedía, Kierkegaard postulará su teoría de la independencia o mejor de la completa emancipación del prólogo respecto del libro.' Su convencimiento de que debe producirse una definitiva ruptura entre libro y prólogo parte también de la 
constatación de la radical otredad del prólogo respecto del libro en cuestión, hecho que lo conduce a afirmar que no existe ninguna necesidad de que el prólogo trate sobre un tema determinado:

En la ciencia moderna, el prólogo ha sido herido de muerte (...) cuando uno empieza el libro con el asunto y el sistema con la nada, ya no considera que quede nada por decir en un prefacio. Esta fue la circunstancia que ocasionó que advirtiera que el prólogo es un género totalmente propio en la creación literaria y que, ya que se lo destierra, es momento de que se emancipe como todo lo demás. De esta manera podrá conservar su validez. Lo excepcional que en los viejos tiempos quedaba relegado al prólogo de un libro, puede ahora encontrar su lugar en un prólogo que no sea prólogo a ningún libro. Si el prólogo y el libro no pueden arreglarse, pues que el uno le conceda al otro la separación. (282)

En diciembre de 1872, Friedrich Nietzsche le envía a la esposa de Richard Wagner un escrito inclasificable titulado Cinco prefacios a cinco libros no escritos encabezados con la dedicatoria: «Para la Señora Cósima Wagner en cordial veneración y como respuesta a preguntas epistolares, escrito con alegre espíritu en los días de Navidad de 1872». Gerard Genette quien se refiere a este texto como a un caso de emancipación total del prefacio, señala: «se dice que la carta que los acompañaba añadía "y que no se escribirán"» (1987:201). Al igual que en el caso precedente de Kierkegaard, el talante de este escrito — si no de la totalidad del libro, sí de su provocador título— es claramente lúdico; los prólogos en cuestión abordaban los siguientes temas: «Sobre el pathos de la verdad»; «Pensamientos sobre el porvenir de nuestros establecimientos de enseñanza»; «El Estado griego»; «Certamen homérico» $\mathrm{y}$ «La relación entre la filosofía schopenhaueriana con una cultura alemana».

Un siglo después, exactamente en 1972, Jacques Derrida publica su libro de ensayos La diseminación y lo encabeza con un apartado titulado «Fuera-de-libro (Prefacios)» en el cual se pronunciará acerca del «Prefacio/Prólogo» acotado, sobre todo, al caso de Hegel y sus escritos filosóficos, aunque también a los Cantos... de Lautreamont y a la obra poética de Novalis y Mallarmé. Sin embargo, el pensador francés va desgranando ciertas particularidades del género que conviene retener. ${ }^{2}$

En primer lugar, Derrida señala igual que lo hiciera Kierkegaard, la necesidad de reconstruir un día la historia y la tipología de los prólogos. Y a continuación, llama la atención, como lo hará poco después Borges, sobre la cuestión de la cronología textual que afecta al género:

Un prefacio (...) enunciaría en el futuro ("van a leer esto») el sentido o el contenido conceptuales de lo que ya habría sido escrito. (...). Para el prólogo (...) el texto es un escrito — un pasado— que, en una falsa apariencia de presente, un autor oculto y todopoderoso, con pleno dominio de su producto, presenta al lector como futuro suyo. Esto es lo que he escrito, después leído y que escribo que van ustedes a leer. (...) El pre del prefacio hace presente el porvenir, lo representa, lo aproxima, y adelantándolo lo pone delante. Lo reduce a la forma de presencia manifiesta. (10-12)

Para Derrida esta pretensión del prólogo resulta irrisoria, no sólo porque la escritura no se mantiene fija en ninguno de esos tiempos (presente, pasado o futuro) sino porque anularía, al extraer un solo núcleo temático o una sola idea directriz, el desplazamiento textual que se opera en la diseminación (13). «Repetición formal», «adorno retórico», «limen notable del texto», puro "protocolo», para el filósofo francés el prefacio es simple anticipación discursiva, y como sólo puede escribirse a posteriori del texto, acaba siendo siempre un posfacio (23). 
Hacia 1975, Jorge Luis Borges recopila los cuarenta prólogos que había compuesto entre 1923 y 1974 y los titula Prólogos con un prólogo de prólogos. Allí, en el texto liminar, insiste en lo que ya Kierkegaard insinuaba en el suyo, la inexistencia de una teoría del prólogo, pero a diferencia del filósofo danés, Borges señala lo innecesario de dicha teoría: la inexistencia de la misma no es un error que deba subsanarse. Asimismo, se pronuncia críticamente contra los prólogos consuetudinarios:

Que yo sepa, nadie ha formulado hasta ahora una teoría del prólogo. La omisión no debe afligirnos, ya que todos sabemos de qué se trata. El prólogo, en la triste mayoría de los casos, linda con la oratoria de sobremesa o con los panegíricos fúnebres y abunda en hipérboles irresponsables, que la lectura incrédula acepta como convenciones del género. (10)

Sin embargo, en escasas y felices ocasiones, el prólogo es mucho más que esto: «El prólogo cuando son propicios los astros, no es una forma subalterna del brindis; es una especie lateral de la crítica» (10). Como vemos, Borges desliza su personal concepción de lo que un prólogo puede llegar a ser, un espacio desde el cual reflexionar críticamente sobre el texto que lo sucede y a la vez sobre la misma instancia preliminar desde la que se enuncia. En este sentido, en el Prólogo a Inquisiones cruzando las coordenadas de lo espacial y lo temporal afirma que «la prefación es aquel rato en que el autor es menos autor (...). La prefación está en la entrada del libro pero su tiempo es de posdata y es como un descartarse de los pliegos y un decirles adiós» (1925:5). Las cursivas son mías). Concebido en términos espaciales, el prólogo sin embargo es un factor decisivo de la cronología textual. ${ }^{3}$ De todos modos, resulta significativa la profusión de metáforas espaciales que se han ido acuñando para hacer referencia al prólogo: «zaguán» (Borges), «umbral», «borde», «aledaños» o «zona indecisa» (Genette), alternativas léxicas que apuntan a señalar la conflictividad entre el adentro y el afuera de un texto. Asimismo, a lo largo del tiempo y de las consiguientes modas literarias, a la denominación de «Prólogo» o «Prefacio» - términos sinónimos según el Tesoro de Covarrubias y el Diccionario de Autoridades - se le suman las de Proemio, Preludio, Preámbulo, Prolegómeno, Discurso preliminar, Presentación, Exordio, Nota, Noticia, Aviso o Advertencia, entre tantos otros.

También Borges se alinea en esa vasta genealogía quevenimos rastreandoy en la que comoveremos más adelante tanto Miguel de Unamuno como Macedonio Fernández ocupan un sitio preferencial, me refiero a la de quienes defienden la emancipación total del prólogo respecto del texto:

La revisión de estas páginas olvidadas me ha sugerido el plan de otro libro más original y mejor, que ofrezco a quienes quieran ejecutarlo (...) El libro que ya estoy entreviendo (...) constaría de una serie de prólogos de libros que no existen. Abundaría en citas ejemplares de esas obras posibles. Hay argumentos que se prestan menos a la escritura laboriosa que a los ocios de la imaginación o al indulgente diálogo, tales argumentos serían la impalpable sustancia de esas páginas que no se escribirán. (10)

Las demandas que desde Kierkegaard en adelante han venido sosteniéndose acerca de la necesidad de elaborar una teoría del prólogo, parecen encontrar parte de su respuesta o al menos una aproximación preliminar en el ensayo Palimpsestos. La literatura en segundo grado que el narratólogo francés Gerard Genette publica en 1982. Allí el autor proponía el concepto de "paratexto» (11-12) para definir todo aquello que rodeaba al texto (categoría en la que incluía naturalmente 
a los prólogos) e insinuaba la necesidad de una investigación futura para ahondar sobre el tema. El fruto de dicha investigación se daría a conocer en 1987 a través de Umbrales, texto en el que abordaba específicamente el estudio del entorno o los alrededores del texto a través de un extenso recorrido por la prehistoria del género prefacial desde Homero, Herodoto y Tucídides, pasando por Tito Livio y el Decamerón, hasta Rabelais. Genette comienza con esta aseveración:

La obra literaria consiste, exhaustiva o esencialmente, en un texto (...) Pero el texto raramente se presenta desnudo, sin el refuerzo y el acompañamiento de un cierto número de producciones, verbales o no, como el nombre del autor, un título, un prefacio, ilustraciones, que no sabemos si debemos considerarlas o no como pertenecientes al texto, pero que en todo caso lo rodean y lo prolongan (...) Este acompañamiento, de amplitud y de conducta variables, constituye lo que he bautizado, el paratexto de la obra. Más que de un límite o de una frontera cerrada, se trata aquí de un umbral que ofrece a quien sea la posibilidad de entrar o retroceder. (1987:7)

A lo largo de su exhaustivo estudio, Genette irá aportando otras taxonomías como la distinción entre «peritexto» (título, prefacio, notas, textualidades que se emplazan dentro del espacio mismo del volumen de un libro) y «epitexto» (entrevistas, epistolarios, diarios íntimos, situados en el exterior del libro y manifestados a través de otros soportes mediáticos). Asimismo, propondrá la distinción entre prólogos autógrafos (compuestos por el autor real o pretendido de un texto), alógrafos (compuestos por una tercera persona diferente del autor) y actorales (compuestos por uno de los personajes del texto), a los que añade las categorías de prólogos auténticos (atribuidos a una persona real), apócrifos (atribuidos falsamente a una persona real) y ficticios (atribuidos a un ser imaginario). Me detengo en estas disquisiciones taxonómicas porque serán de cierta relevancia para abordar el caso de la novela Niebla de Miguel de Unamuno, texto curiosamente no contemplado por Genette en su estudio.

Existen, además, dos interesantes aportes que podemos sumar a este rápido recorrido que venimos realizando. El primero de ellos, el estudio pionero que Alberto Porqueras Mayo publica en 1957 en torno al prólogo en el Siglo de Oro español. Lo que se propone el autor es demostrar que el prólogo constituye un género literario en sí mismo y que tanto estilística como tipográficamente es algo aparte del libro al que precede. Uno de los rasgos que subraya es la extrema «permeabilidad» que existe entre libro y prólogo; esta «doble participación del prólogo en el libro» es la que motiva que aquel pueda pertenecer tanto al Narrautor, como a los personajes (Vauthier:458). Resulta evidente tras la lectura de este trabajo que el prólogo hasta el siglo XVII inclusive fue un formato literario altamente codificado, atado al rigor preceptivo y a los usos y costumbres imperantes. Esta comprobación quizá torne más comprensibles los numerosos intentos que a partir del siglo XVIII y hasta la actualidad se han llevado a cabo para subvertir lo anquilosado del molde.

El segundo aporte es el estudio de Montoya Martínez e Isabel de Riquer (1998) en torno al prólogo literario en la Edad Media, estudio centrado en un enfoque retórico del género prologal que hace hincapié en las múltiples y variadas estrategias discursivas que se despliegan en este género tendientes todas ellas a la persuasión del receptor. ${ }^{4}$

Eva Álvarez Ramos retoma esta línea especulativa en torno al prólogo en varios de sus trabajos. La hipótesis central de la autora es que el grupo textual formado por los prólogos sería una forma del llamado "genus demostrativum» por lo cual todos ellos apelan a una exposición discursiva 
con un marcado carácter argumentativo cuyo propósito - aunque el tono empleado raye lo humorístico o lo anecdótico— es siempre persuadir al lector (2002a:65 y 2002b:371). Y propone una definición del mismo:

El prólogo es un género en prosa, escrito en primera persona, de carácter breve, que nos pone al igual que los del teatro clásico en antecedentes de lo que nos vamos a encontrar. (...) En él tienen cabida la ficción literaria, los elementos doctrinales, lo anecdótico y lo biográfico y no es ni un relato, ni un tratado, ni un artículo periodístico, ni una biografía (2002b:372)

Con esto de los comentarios encorchetados (...) va a parecerle a algún lector algo así como esas cajitas de laca japonesa que encierran otra cajita y ésta otra y luego otra más (...) y al último una cajita... vacía. Pero así es el mundo y la vida. Comentarios de comentarios y otra vez más comentarios. ¿Y la novela? Si por novela entiendes, lector, el argumento, no hay novela.

Miguel de Unamuno, Cómo se hace una novela (1927)

Si bien en la obra narrativa de Miguel de Unamuno abundan los prólogos, nos detendremos especialmente en aquellos en los que el autor reflexiona sobre el género en un gesto claramente autorreferencial. No obstante, el caso de los prólogos a segundas ediciones resultan, por otras razones, igualmente significativos. Es el caso del Prólogo a la segunda edición de Abel Sánchez (1928), escrito desde el destierro francés, y es el caso también de su primera novela, Paz en la Guerra publicada en 1897 y que aparece desprovista de prólogo hasta su segunda edición de 1923. En él, resulta interesante el distanciamiento crítico del autor que se pronuncia sobre su obra inaugural —un texto compuesto todavía en clave realista sobre un episodio de las guerras carlistas- desde la perspectiva del creador ya consagrado de «nivolas»: «En esta novela hay pintura de paisaje y dibujo y colorido de tiempo y de lugar. Después he abandonado este proceder, forjando novelas fuera de lugar y tiempo determinados, en esqueleto, a modo de dramas íntimos» (1946:319).

Es precisamente en el Prólogo-Epílogo a la segunda edición de Amor y pedagogía (1902) que Unamuno ofrece su conocida definición del concepto de "nivola» ${ }^{6}$. En realidad, esta novela/nivola se encuentra rodeada de paratextos, desde la dedicatoria — «El Autor dedica esta obra al Lector»—, pasando por el Prólogo apócrifo y el Prólogo-Epílogo a la segunda edición hasta llegar al Epílogo y al Apéndice. ${ }^{7}$ Se trata de un texto inclasificable —recordemos que en él tienen cabida fórmulas matemáticas, dibujos, diagramas, moldes para plegar el papel incluidos en un curioso «Tratado de cocotología»— ${ }^{8}$ cuya extravagante concepción se liga íntimamente a un espíritu entre lúdico y absurdo en un intento por movilizar al lector.

Resulta innegable la autoconciencia que el propio Unamuno tenía acerca de la novedad que encerraba su propuesta estética así como la gran expectativa que albergaba acerca de la recepción de su obra, y de esta preocupación da clara muestra su epistolario. En marzo de 1902, mientras espera ansiosamente la aparición de Amor y Pedagogía, Unamuno menciona en carta a Bernardo Candamo el posible «escándalo que pueda producir, sobre todo su prólogo y epílogo» (1902b:113). ${ }^{9}$ Efectivamente, sobre todo en el Epílogo de esta novela, el autor extrema la provocación en un intento por emanciparse de la tiranía del discurso lógico: «¿Significa ni puede significar la libertad 
otra cosa que la emancipación de la lógica, que es nuestra más triste servidumbre?» (1981:138). En este epílogo el autor justifica a través de razones de índole puramente mercantilistas su escritura artística pero lo denuncia desde un texto altamente provocador que transgrede las convenciones del género y que por ello mismo nos invita a leer todo lo que en él se declara en clave irónica:

Ya yo, por mi parte, previendo que la obra resultara demasiado breve para los propósitos del editor, la hinché mediante el prólogo que la precede (...) mas ni aún así parece que he llegado a la medida (...). Opto por añadirle un epílogo con lo cual se consigue, además, que tenga mi libro la tan acreditada división tripartita, constando de prólogo, logo y epílogo. (125-126)

$\mathrm{Al}$ igual que en el «Soneto a Violante» de Lope, el texto va haciendo lo que dice; en términos pragmáticos diríamos que a través de un gesto autorreflejo el texto ejecuta su significado. Por otro lado, es indiscutible el estrecho vínculo que la estética unamuniana mantiene con la escritura del Siglo de Oro español. Si Niebla (1914) se emparenta claramente con La vida es sueño, y Amory Pedagogía (1902) lo hace con Lope, La tía Tula (1920) —y esto es puesto de manifiesto en el «Prólogo del autor (que puede saltar el lector de novelas)»— ostenta raíces quijotescas y teresianas (1921:19).

También en 1920 aparece la muy cervantina Tres novelas ejemplares y un prólogo en cuyo extenso Prólogo leemos: «Lo mismo pude haber puesto en la portada de este libro: Cuatro novelas ejemplares. ¿Cuatro? ¿Por qué? Porque este prólogo es también una novela. Una novela, entendámonos, y no una nivola; una novela» (9). Resulta evidente el lugar central que asigna Unamuno a este problema teórico de lo liminar y lo central, del texto y los paratextos, de lo abierto y lo cerrado, de lo concluso y lo inconcluso, en síntesis, de la obra perfecta/total del realismo y del esbozo de obra del siglo XX. Problemática que hallará su más cabal expresión en Niebla.

Efectivamente, Niebla, la novela más traducida y conocida de Unamuno es, por su índole autorreferencial, la que mejor sintetiza todo lo que aquí venimos señalando. Saturada de paratextos - Prólogo, Post-Prólogo, Metálogo, Epílogo y Apéndice- esta nivola condensa toda la problemática teórica que desde Kierkegaard y hasta la actualidad se viene planteando respecto de la cuestión de los bordes - el adentro y el afuera - de un texto.

Gerard Genette considera que una especie relativamente clásica es la del prólogo actoral ficticio: «Nada impide — afirma — que en principio un relato heterodiegético (...) sea prologado por uno de sus personajes» (1987:161), y éste es el caso de Niebla, prologada por Víctor Goti, uno de los personajes de la ficción narrativa. En este sentido, Bénédicte Vauthier sostiene que Víctor Goti al salir del ámbito ficticio e instalarse en el «entredós» paratextual ejemplifica la permeabilidad del prólogo respecto del libro (458). Pero este inocente juego literario tuvo sus consecuencias pragmáticas y son varios los críticos que dan cuenta de la existencia de fichas bibliográficas de diversas bibliotecas (entre ellas la del British Museum) donde se registra el nombre de Víctor Goti como el del autor de un único texto: el Prólogo de Niebla de Miguel de Unamuno. ${ }^{10}$ Seguramente, el hecho de que en la primera edición (Biblioteca Renacimiento, 1914) el nombre del prologuista figurara en la portada misma del libro, ayudó a que este engaño prosperara.

El artificio elegido apunta, además, a equiparar el estatuto existencial del personaje de ficción con el de su autor, equiparación de categorías existenciales que socavan la credibilidad autoral y extreman el cuestionamiento de la noción misma de autoría cuando se nos dice que existe un vínculo de consanguinidad entre ambos: «Parece que tengo algún lejano parentesco con don Miguel 
ya que mi apellido es el de uno de sus antepasados» (1914:18). De este modo, Unamuno rompe con el carácter ritual y previsible que rigió a este limen textual desde la Antigüedad; subvirtiendo las leyes del género, elige, además, que sea un desconocido quien prologue a un autor consagrado — «Pero es que nos hemos puesto de acuerdo don Miguel y yo para alterar esta perniciosa costumbre invirtiendo los términos» (17. Las cursivas son mías), y al hacerlo viola también el horizonte de expectativas de sus lectores: «Parecerá acaso extraño a alguno de nuestros lectores...». El carácter provocador y revulsivo de la escritura unamuniana trasciende como vemos el espacio del corpus textual propiamente dicho (la novedosa concepción de su teoría de la nivola) y alcanza a los mismos márgenes del texto. A través de ambos gestos el pensador bilbaíno apunta sistemáticamente a deconstruir el perfil del lector promedio de la época, su simplicidad, su ingenuidad, su candidez, su escasa cultura, su consecuente recelo, un público incapaz de interpretar las sutilezas - juego entre realidad/ficción, entre comedia/ tragedia, empleo de la ironía como clave de lectura, conceptismo — de su propuesta estética: «A ver si el ingenio colectivo de nuestro pueblo se va agilizando y sutilizando poco a poco» (22).

En una primera instancia, el Post-prólogo firmado por Miguel de Unamuno parece romper con el intento del prólogo a través de la firme presencia autoral que desmiente el intento de equiparación entre el ente de ficción y el sujeto real — «Y debe andarse mi amigo y prologuista Goti con mucho tiento en discutir así mis decisiones, porque si me fastidia mucho acabaré por hacer con él, lo que con su amigo Pérez hice» (29-30)—, sin embargo, una vez más, Unamuno somete a su lector al sutil e incesante juego de la ironía porque al tiempo que afirma su auctoritas reafirma la relación de amistad existente entre él y su criatura.

Por su parte, este juego de íntima complicidad con su lector se continúa en el Metálogo o «Historia de Niebla», fechada y firmada por Unamuno en Salamanca en febrero de 1935. En él se insiste en el carácter activo y participante que debería regir todo proceso de lectura; frente a un lector demasiado atado a las convenciones de la narrativa realista del siglo XIX, Unamuno propone para el suyo, para el lector de sus nivolas, el rol de "colaborador», de "co-creador»: "pero el lector no resiste todo, no tolera que se le saque de su sueño y se le sumerja en el sueño del sueño (...). No quiere que le arranquen la ilusión de realidad» (35).

Dos paratextos cierran la nivola, el Epílogo u «Oración fúnebre», un soliloquio remedo del coloquio cervantino puesto en boca de Orfeo, el perro del protagonista, y el Apéndice: «Una entrevista con Augusto Pérez». Sin embargo, en ambos se exhibe orgullosamente la deliberada transgresión de las convenciones genéricas: «Suele ser costumbre al final de las novelas, y luego que muere o se casa el héroe o protagonista, dar noticia de la suerte que corrieron los demás personajes. No la vamos a seguir aquí» (219).

La ironía y la parodia recorre la oración fúnebre del perro quien aborda cuestiones filosóficas, metafísicas y lingüísticas — "Qué extraño animal es el hombre (...). En cuanto le ha puesto nombre a algo, ya no ve este algo, no hace sino oír el nombre que le puso, o verle escrito»— apoyándose en citas eruditas de Platón o de la Biblia." Por su parte, el Apéndice nos enfrenta a la declaración más explícita de las muchas que ha producido Unamuno en torno a la cuestión del prólogo:

¿A qué vendrá todo este proemio?, se preguntará alguno de mis lectores. Y yo le digo: ¿Y si todo éste mi ensayo de hoy no fuese él más que un proemio? ¿Por qué no ha de hacer uno una obra que toda ella sea prólogo o prefacio? ¿O es que en rigor las más de las obras escritas son más que prólogos? Los libros mejores no son sino prólogos, prólogos de un libro que no se ha de escribir jamás, afortunadamente. (228) 
Resulta evidente el íntimo parentesco que estas reflexiones unamunianas mantienen con las previas de Kierkegaard o Nietzsche así como con las posteriores de Borges o de Macedonio Fernández. Efectivamente, son muchos los aspectos en que confluyen la obra del español y del argentino Macedonio Fernández. Sin embargo, hasta la fecha no se ha profundizado suficientemente en la investigación de las estrategias de discurso y concepciones estéticofilosóficas que ambas escrituras exhiben en común. ${ }^{2}$ En primer lugar, cabe señalar que se trata de escritores coetáneos y que Macedonio fue lector del escritor vasco, al punto de proponer como una de sus identidades ficticias el nombre de «Ningunamuno», revelando de este modo la voluntad de entrar en diálogo con la obra del español: «Por eso yo — sigo el paréntesis por fuera para que no se me moteje de digresivo como Unamuno, que nunca escribe sobre lo que trata-, por eso yo, que a veces estoy tan poco y tenue, que me parece que me llamo Ningunamuno...» (1975:17). En segundo lugar, sabemos que hacia 1929 Macedonio le envió al escritor vasco dos cartas, junto a un ejemplar de No todo es vigilia..., cartas que Unamuno nunca respondió (García:73). ${ }^{13}$ En tercer lugar, contamos con el testimonio de Borges quien nos dice de Macedonio: «Esta superstición de lo argentino lo movió a opinar que Unamuno, y los otros españoles, se habían puesto a pensar, y muchas veces a pensar bien, porque sabían que serían leídos en Buenos Aires» (1975:81).

Dentro de la común proliferación paratextual —baste recordar que Museo de la novela de la Eterna (1938) consta de 57 prólogos—, ${ }^{14}$ llama especialmente la atención el intento de formulación de una teoría del prólogo que ponga en cuestión las usuales determinaciones o convenciones genéricas, llegando a insinuarse que resulta del todo arbitraria la tradicional distinción entre texto y paratexto: «Estos ¿fueron prólogos? y ésta ¿será novela?» reza la página que separa los supuestos prólogos de la supuesta novela macedoniana. El lugar privilegiado que tanto Macedonio como Unamuno asignan al problema teórico de lo marginal versus lo central, de lo abierto versus lo cerrado, de lo concluso versus lo inconcluso, en síntesis, de la obra enfrentada al texto (Barthes) responde a una común concepción estética que apuesta por el fragmento, el esbozo o el proyecto provisional deconstruyendo por igual la mímesis realista del XIX.

Si bien es cierto que los prólogos han existido desde la Antigüedad, y ya Cervantes en el suyo al Quijote inaugura alguno de los aspectos que aquí venimos subrayando, lo novedoso parece ser este ejercicio de reflexionar - de teorizar- sobre el género en un insistente gesto autorreferencial: escribir desde el prólogo sobre el prólogo. Gesto que conduce simultáneamente a la idea de la emancipación del prólogo que da por tierra con el carácter subsidiario del mismo subvirtiendo su significado al autonomizarse del libro. A principios del siglo XX el prólogo tradicional ha perdido el prestigio de antaño y se ha convertido en mero "género propagandístico» (Vauthier:461). Lo que estos autores llevan a cabo es un poderoso y simultáneo ejercicio de deconstrucción y resignificación del mismo, y al hacerlo refundan el género asignándole nuevas y provocadoras funciones.

En el prólogo titulado «Paul Valery: el cementerio marino», Borges afirma sobre la traducción algo que sin embargo es válido para encarar también la cuestión implícita en esta concepción abierta de los prólogos: «Presuponer que toda recombinación de elementos es obligatoriamente inferior a su original, es presuponer que el borrador 9 es obligatoriamente inferior al borrador $\mathrm{H}$ -ya que no puede haber sino borradores. El concepto de texto definitivo no corresponde sino a la religión o al cansancio» (251).

Y ya Unamuno había dejado dicho algo muy similar cuando en Cómo se hace una novela sentenciaba: «El lector que busque novelas acabadas no merece ser mi lector» (1978:171). Cervantes, 


\begin{abstract}
Kierkegaard, Nietzsche han sido auténticos precursores de Unamuno, así como éste último lo fue de Borges y de Macedonio. Novelas como prólogos; prólogos como novelas son formulaciones que no hacen sino confirmar una firme defensa de la reversibilidad genérica. Como vemos, el controvertido escritor vasco empleó sus paratextos para discutir consigo mismo, con la institución literaria, con los agentes del campo intelectual de la época, con las convenciones genéricas y con su lectorado, y lo hizo indistintamente a través de personajes ficticios — como es el caso del Víctor Goti en Niebla -, de voces apócrifas como la del pseudo prologuista de Amory Pedagogía o a través de monodiálogos o autodiálogos autorales. Sin duda, el estudio complementario de estos umbrales textuales en tanto manifestación de una "función autopoética»" ${ }^{15}$ arrojaría también valiosísima información para reconstruir la estética de la producción literaria del autor.
\end{abstract}

\section{Notas}

1 También Derrida tomará el caso de Hegel y sus prólogos como tema de estudio sobre el género.

2 El mismo Derrida se interroga si los prólogos constituyen propiamente un género (14).

3 También Unamuno se referirá a esta cuestión en el Prólogo a sus Tres novelas ejemplares donde afirma: «Este prólogo es posterior a las novelas a que precede y prologa como una gramática es posterior a la lengua que trata de regular y una doctrina moral a los actos de virtud o vicio que con ellos tratan de explicarse» (1920:11).

4 Recordemos que ya Genette señalaba como función del prólogo la de retener al lector a través del despliegue de todo el utillaje propio de la retórica.

5 Es también el caso del Prólogo a su ensayo Cómo se hace una novela (1927) escrito desde el exilio fronterizo de Hendaya.

6 «A esta novela precedió otra de las mías, que fue Paz en la Guerra, relato histórico de la guerra civil carlista de 1874, y le siguieron otras ya en tono distinto. De éstas que para dar asidero a la terrible pereza mental de nuestro público — no de nuestro pueblo- llamé en un momento de mal humor nivolas. Relatos dramáticos acezantes, de realidades íntimas, entrañadas, sin bambalinas ni realismos en que suele faltar la verdadera, la eterna realidad, la realidad de la personalidad» (1981:16).

7 El Apéndice y con él la novela concluye así: «Y con esto termino yo, por mi parte, este Apéndice, porque si después del prólogo-epílogo de esta edición y el prólogo y el epílogo de la primera me doy a hinchar este Apéndice, puede inflamarse y padecer esta obra de apendicitis, que es una de las peores dolencias que puede aquejar a una obra científica o literaria» (1981:169).

$8 \mathrm{El}$ neologismo «cocotología» lo acuña el mismo Unamuno para traducir la técnica del origami o papiroflexia, arte al que era muy afecto.

9 Idéntica preocupación revela ante la inminente aparición de su inicial obra poética, Poesías, en 1907. Cfr. Ferrari.

10 Cfr. Ribbans (109); Fernández (18); y Øveraas (17).

11 A través de la vanguardista técnica de la desautomatización sobre la que teorizara Víctor Schklovski hacia 1917, el discurso de Orfeo adelanta muchas de las posturas posestructuralistas sobre el lenguaje. Citemos a modo de ejemplo este poema de Guillermo Carnero: «Mira el breve minuto de la rosa/ Antes de haberla visto, sabías ya su nombre/ y ya los batintines de tu léxico, aturdían tus ojos/ - luego, al salir al aire, fuiste inmune/ a lo que no animara en tu memoria/ la falsa herida en que las cuatro letras/ omiten esa mancha de color: la rosa tiembla, es tacto./ Si llegaste a advertir lo que no tiene nombre/regresas luego a dárselo, en él ver: un tallo mondo, nada;/ cuando otra se repite y nace pura/ careces de más vida, tus ojos no padecen agresión de la luz,/ sólo una vez son nuevos» (Carnero:250).

12 Entre los muchos aspectos dignos de un pormenorizado estudio comparativo señalo: el cruce entre literatura y filosofía, la disolución del yo del autor en la ficción narrativa, la postulación de un rol activo para el lector, la afinidad entre la «nivola» unamuniana y la «Belarte conciencial» macedoniana, la introducción del componente biográfico en la ficción, la común preocupación por fundar una "poesía del pensar» (Macedonio) y una «poesía meditativa» (Unamuno), entre muchos otros.

13 Resulta extraño este silencio de Unamuno que se definía a sí mismo como un «epistológrafo» por su intensa dedicación a 
la correspondencia epistolar; de todos modos hay que atender a la circunstancia de que para 1929 el escritor vasco se encontraba todavía en el exilio francés en Hendaya.

14 Para citar sólo algunos títulos significativos: «Prólogo a mi persona de autor»; «Prólogo que cree saber algo, no de la novela, pues ello es incompetente a los prólogos»; «Prólogo 568»; «Prólogo primero de la novela para el lector corto»; «Prólogo del perso- naje prestado al autor»; «Prólogo que se siente novela»; «Nota de posprólogo», entre otros.

15 Con el término de «autopoética» se designan las reflexiones y declaraciones autorales en torno al quehacer literario en general y a la práctica poética en particular factible de rastrear a partir de epistolarios, prólogos, notas, etc. Cfr. Rubio Montaner (188), Demmers (7-15), Casas (217).

\section{Bibliografía}

Álvarez Ramos, Eva (2002a). «El prólogo literario en el siglo XX y la retórica clásica: de las partes orationis a los tópicos más comunes». Ogigia. Revista electrónica de estudios hispánicos 1, 61-73. Web. (2002b). «Aproximaciones a una teoría del prólogo: el caso extremo de Borges». La palabra es futuro: filólogos del nuevo milenio, 365-378.

Borges, Jorge Luis (1925). Inquisiciones. Buenos Aires: Proa.

(1927). «Palabras finales (prólogo breve y discutidor)». Antología de la moderna poesía uruguaya, 1900-1927. Buenos Aires: El Ateneo, 219-221.

(1975). Prólogos con un prólogo de prólogos. Madrid: Alianza, 1998.

Carnero, Guillermo (1998). Dibujo de la muerte. Obra Poética. Madrid: Cátedra.

Casas, Arturo (1999). «La función autopoética y el problema de productividad histórica», en José Romera Castillo

y Francisco Gutiérrez Carbajo, editores. Poesía histórica y (auto)biográfica (1975-1999). Madrid: UNED, 209-218. Demers, Jeanne (1993). «Présentation. En liberté, la poétique». Études françaises, (29)3, 7-15. Web.

Derrida, Jacques (1975). La diseminación. Madrid: Fundamentos, 1997. Traducción de José Martìn Arancibia. Fernández, Ana María (1991). Teoría de la novela en Unamuno, Ortega y Cortázar. Madrid: Pliegos.

Fernández, Macedonio (1975). Relatos: cuentos, poemas y misceláneas. Volumen VII. Buenos Aires: Corregidor. Ferrari, Marta B. (2014). Unamuno: obrero del pensamiento.Estudio preliminary Antología poética. Villa María: EDUVIM.

García, Carlos (Ed.) (2000). Correspondencia Macedonio-Borges. 1922-1939. Buenos Aires: Corregidor. Genette, Gerard (1982). Palimpsesto. La literatura en segundo grado. Madrid: Taurus, 1989. Traducción de Celia Fernández Prieto. (1987). Umbrales. Buenos Aires: Siglo XXI, 2001. Traducción de Susana Lage.

Kierkegaard, Søren (1844). Migajas filosóficas. El concepto de angustia. Prólogos. Volumen 4/2. Madrid: Trotta, 2016. Traducción de Darío González y Óscar Parcero.

Montoya Martínez, Jesús e Isabel de Riquer (1998). El prólogo literario en la Edad Media. Madrid: UNED.

Nietzsche, Friedrich (1872). Cinco prefacios a cinco libros no escritos. Web.

$\emptyset$ veraas, Anne Marie (1993). Nivola contra Novela. Salamanca: Ediciones Universitarias.

Porqueras Mayo, Alberto (1957). El prólogo como género literario: su estudio en el Siglo de Oro epañol. Madrid: Consejo Superior de Investigaciones Científicas.

Ribbans, Geoffrey (1971). Niebla y Soledad. Aspectos de Machado y Unamuno. Madrid: Gredos.

Rubio Montaner, Pilar (1990). «Sobre la necesaria integración de las poéticas de autor en la Teoría de la Literatura». Castilla. Estudios de Literatura 15, 183-197.

Unamuno, Miguel de (1902a). Amory pedagogía. Madrid: Espasa-Calpe, 1981. (1902b). «Carta a Bernardo G. de Candamo», en Laureano Robles, editor. Epistolario inédito. Madrid: Espasa Calpe, 1991, 83-121. 
(1914). Niebla. Madrid: Círculo de amigos de la Historia, 1979.

(1920). Tres novelas ejemplares y un prólogo. Madrid: Espasa-Calpe, 1964.

(1921). La tía Tula. Navarra: Salvat, 1970.

(1930). San Manuel Bueno, mártir. Cómo se hace una novela. Madrid: Alianza, 1978.

(1946). Obras selectas. Madrid: Pléyade.

Vauthier, Bénédicte (1998). «Niebla de Miguel de Unamuno. Una novela ejemplar», en Florencio Sevilla y Carlos Alvar, editores. Tomo II. Actas del XIII Congreso de la Asociación Internacional de Hispanistas. Madrid, 6 al 11 de julio, 454-462. 